\title{
Investigation of Stem-like Cells Role in Regional Radiosensitivity of the Lung
}

Ola M Maria ${ }^{1,2,3^{*}}$ Ahmed M Maria ${ }^{4}$ Norma Ybarra $^{1,3}$ Krishinima Jeyaseelan $^{1}$ Sangkyu Lee ${ }^{1}$, Jessica Perez ${ }^{1}$, Shirley Lehnert $^{1,3}$, Lyne Kharbotly ${ }^{5}$, Sergio Faria ${ }^{3}$, Monica Serban', Jan Seuntjens ${ }^{1,3}$ and Issam EI Naqa ${ }^{1,3}$

${ }^{1}$ Department of Oncology, Medical Physics Unit, McGill University, Montreal, Quebec, Canada

${ }^{2}$ Department of Oral Biology, Faculty of Dentistry, Mansoura University, Mansoura, Egypt

${ }^{3}$ Department of Oncology, Radiation Oncology Division, McGill University Health Centre, Montreal, Quebec, Canada

${ }^{4}$ Faculty of Medicine, Tanta University, Tanta, Egypt

${ }^{5}$ Collège International des Marcellines, 815 Upper Belmont, Westmount, Quebec, Canada

\begin{abstract}
Objective: Lung is a complex organ with puzzling patterns of radiosensitivity, depending on both the volume and the region of the lung irradiated. In this study, we aimed to investigate stem-like cells distribution in lung lobes and their potential role in regional radiosensitivity and incidences of radiation-induced lung damage (RILD)

Methods: Fifteen male Sprague-Dawley rats (8 weeks, 200-250 g) were grouped into two groups: control (sham irradiated, $n=6$ ) and treatment (irradiated, $n=9$ ). The treatment group received 3 regimens of whole thorax $x$-ray doses and divided into 3 subgroups: $12 \mathrm{~Gy}(\mathrm{n}=3), 16 \mathrm{~Gy}(\mathrm{n}=3)$ and $20 \mathrm{~Gy}(\mathrm{n}=3)$, and monitored for 16 weeks post-radiation. Immunohistochemistry techniques were employed to localize and quantify the distribution of type II pneumocytes, Clara cells and cluster of differentiation (CD) positive stem cells $\left(\mathrm{CD} 24^{+}, \mathrm{CD} 44 \mathrm{v} 6^{+}, \mathrm{CD} 73^{+}\right)$, in the upper, middle and lower lobes of the right lung in all rats.

Results: The upper lobe was found to harbour more stem-like cells compared to the middle/lower lobes $(p<$ 0.05). The middle and lower lobes contained comparable percentages of different stem-like cells. All stem-like cells tested were distributed unsystematically in the lung tissue with no specific identifiable niches.

Conclusion: The upper lobe harbours more population of stem-like cells compared to the lower lobe, this might explain the variation in regional radiosensitivity, with the lower lung lobe being more prone to radiation injury compared to the upper lobe. No specific stem cell niche could be identified in our study. These results may support the development of new-targeted radioprotection strategies to reduce incidences of RILD during radiotherapy.
\end{abstract}

Keywords: Radiation-induced lung damage; Regional radiosensitivity; Stem-like cells; Irradiation

\section{Introduction}

Lung tissue exposure to radiation can occur during the treatment of a variety of cancers such as lung, oesophageal, breast, and various childhood malignancies, leading to increased risk of radiationinduced lung disease (RILD). RILD manifests in up to $30 \%$ of thoracic irradiations, generally, in the forms of two phases: acute inflammatory pneumonitis ( 2 - 3 months post irradiation) and chronic pulmonary fibrosis (4 - 12 months post irradiation) [1-3]. RILD is a major limiting factor to radiotherapy treatment success and is a major obstacle to the application of advanced dose escalation modalities and promising hypofractionation radiotherapy regimens [4-6]. Therefore, developing alternative strategies to protect lung function from RILD onset is essential. The mechanisms involved in the initiation and development of RILD remain incompletely understood; however, many studies have reported a cyclic inflammatory response associated with proinflammatory cytokines [7-9]. It is well established from pre-clinical and clinical studies that radiation effects are not only dependent on the radiation dose but also on the volume of lung tissue being exposed to radiation and the region of the lung being irradiated [10-16].

It is recognized that the lung is a complex organ with puzzling patterns of radiosensitivity, depending on both the volume and the region of the lung irradiated. This has been postulated to be related to the variability in stimulated cytokine production and to the distribution of so-called functional subunits (FSU) in the radiosensitive regions $[17,18]$. Other proposed factors included coincidental radiation of the heart [19] or the non-homogeneous distribution of blood supply resulting from impairment following radiotherapy [20,21], which might play a role in the variations of regional radiosensitivities. Some of these patterns have been corroborated by clinical dose-volume analysis studies [4,22]. An alternative hypothesis that we are exploring in this work, is that the observed variability in regional radiosensitivities might be attributed to differences in the distribution of lung progenitor and stem cell populations across various regions of the irradiated lung. This may further imply that radiosensitive regions harbour less of these "stem-like" (stem/progenitors) cell populations and therefore, new strategies for radioprotection are to be considered to spare these cells during radiation, if possible.

There are many open questions regarding tissue repair and/or remodelling mechanisms of many organs including the lung. Some studies declared that adult tissues harbour stem/progenitor cells that are recruited during the repair process, while other studies reported that

*Corresponding author: Ola M Maria, Department of Oncology, Medical Physics Unit, McGill University, Montreal General Hospital, Radiation Oncology Division, 1650 Cedar Ave, Québec, Canada, Tel: +15149341934 (Extn.: 44157); Fax: +15149348229; E-mail: ola.maria@mail.mcgill.ca

Received July 15, 2015; Accepted August 04, 2015; Published August 06, 2015

Citation: Maria OM, Maria AM, Ybarra N, Jeyaseelan K, Lee S, et al. (2015) Investigation of Stem-like Cells Role in Regional Radiosensitivity of the Lung. J Stem Cell Res Ther 5: 298. doi:10.4172/2157-7633.1000298

Copyright: @ 2015 Maria OM, et al. This is an open-access article distributed unde the terms of the Creative Commons Attribution License, which permits unrestricted use, distribution, and reproduction in any medium, provided the original author and source are credited. 
bone marrow-derived stem/progenitor cells participate in the repair of most organs [23-25]. Lung tissue has a substantial regenerative capacity through proliferation and differentiation of resident Clara cells and type II pneumocytes to replace various tissue compartments following lung injury [26]. Bone marrow as the main source of adult stem cells, harbours stem cells that reside in localized specific microenvironment; commonly referred to as a stem cell niche [27] and many studies have suggested that other organs might have their own localized stem cell niches including the lung. However, it is still unclear whether a single multipotent stem/progenitor cell in the lung gives different tissue compartments. Many lung stem/progenitor cells have been reported, including tracheal gland duct cells, tracheal basal cells, Clara cells, pulmonary neuroendocrine cells and type II pneumocytes [28]. Recently, bone marrow stem/progenitor cells have been reported to differentiate into many cell types in multiple tissues [23-25], including the lung, where bronchial epithelial cells, type I and II pneumocytes have been demonstrated to be derived from donor bone marrow cells [29-32], However, to our knowledge, the relationship between stem/ progenitor cells distribution in the lung and regional radiosensitivity has not been investigated before.

In order to characterize and in situ localize these stem-like cells in lung tissue and investigate their potential role in regional radiation response of the lung, we used an experimental rat model of RILD with endpoint of pulmonary fibrosis following different radiation doses. We evaluated the changes in the stem-like cells population (Clara cell secretory protein, surfactant B, CD24, CD44v6, CD73) within the lung parenchyma as further discussed below. In these experiments, the rats received different radiation doses of $0,12,16$, and 20 Gy that resulted in different observed morbidities. In this study, other functional lung measures (i.e. breathing rate, $\mathrm{CO}_{2}$ and oxygen saturation) and imaging information were recorded to make sure that rats developed RILD but these data were not included in this manuscript so as not to dilute the main focus of the study. We believe that better characterization of the radiation response of these stem-like cells is critical to improve our understanding of the pathophysiology of RILD. Moreover, if our hypothesis that stem-like cells play a pivotal role in radiation sensitivity of the lung is proven correct this might help in developing novel targeted therapies to mitigate the onset of RILD and pave the way for new directions in radiotherapy protection.

\section{Material and Methods}

\section{Animals}

Fifteen male Sprague-Dawley rats (Charles River laboratory) aged 8 weeks and weighed 200-250 g were used. The animals were housed at an accredited animal facility at the Montreal General Hospital and all the study procedures were approved by the institutional Animal Care Committee at McGill University.

The rats were divided into two main groups: control (sham irradiated, $n=6$ ) and treatment (irradiated, $n=9$ ) groups. The treatment group received 3 regimens of whole thorax $\mathrm{x}$-ray doses and was divided into 3 subgroups: 12 Gy $(n=3), 16$ Gy $(n=3)$ and 20 Gy $(n=3)$. All animals were allowed sterilized food and water ad libitum. Rats were checked daily, and those showing continuing distress or significant signs of morbidity, such as poor grooming along with hunching, lack of eating or drinking, or severe respiratory problems were euthanized.

\section{Radiation}

Isoflurane anaesthetized rats were placed in a Plexiglas jig and given 12,16 or 20 Gy with anterior-posterior (AP) and PA beams to whole thorax on a $6 \mathrm{MV}$ linear accelerator (LINAC) calibrated for small animal radiation with a dose rate of $600 \mathrm{~Gy} / \mathrm{min}$ with the LINAC isocenter placed at lung midplane at $100 \mathrm{~cm}$ surface-to-axis distance. Whole thorax radiation was planned by using 3 Dimension conformal radiotherapy (3D-CRT) planning with MLC subfields performed for each animal using the Eclipse ${ }^{\mathrm{T}}$ treatment planning system (Varian Medical Systems, Inc., Palo Alto, CA, USA). The radiation dose was calculated by using the Eclipse ver10 AAA algorithm with the heterogeneity correction option turned $\mathrm{ON}$ as commissioned clinically in our institute. Animal setup and position verification was done at the time of delivery by using onboard imaging. Rats irradiated with $12 \mathrm{~Gy}$ and $16 \mathrm{~Gy}$ and their age-matched controls $(\mathrm{n}=3)$ were sacrificed at the age of 24 weeks ( 16 weeks post irradiation) while rats irradiated with 20 Gy and their age-matched controls $(n=3)$ were sacrificed at 12 weeks of age ( 4 weeks post irradiation) because of morbidities.

\section{Immunohistochemistry (IHC)}

Formalin fixed paraffin-embedded tissue slides prepared $(5 \mu \mathrm{m}$ thickness) from the right upper, middle and lower lung lobes of control and irradiated rats were deparaffinised and rehydrated in different alcohol series followed by two washing steps in Phosphate Buffer Saline (PBS) for $5 \mathrm{~min}$ each. The slides were incubated $15 \mathrm{~min}$ in boiling 1x Ethylenediaminetetraacetic acid (EDTA) solution $(\mathrm{pH}=8.0)$ for heat-induced epitope retrieval followed by two washing steps in PBS for $5 \mathrm{~min}$ each. Endogenous peroxidase and biotin activities were blocked with $3 \%$ hydrogen peroxide and serum-free protein block, respectively. The primary antibodies (described below) were diluted 1:50 in PBS containing serum-free protein block and slides were incubated overnight at $4^{\circ} \mathrm{C}$ in a humid chamber. A secondary broadspectrum antibody kit (Zymed Labs, Burlington, ON, Canada) was used according to the manufacturer's recommendations with adding 3-amino-9-ethyl-carbazole (AEC, Zymed Labs) chromogen to observe the reaction color in red. Then, slides were counterstained with Mayer's haematoxylin (Fisher Scientific, Kalamazoo, MI).

We used the following selected antibodies with proper controls in each case: rabbit anti-Clara cell secretory protein (CCSP) for detection of Clara cells (Millipore, MA, USA); CD44v6 (Millipore, MA, USA) for detection of possible mesenchymal stem-like cells in lung tissue, CD44 is a transmembrane glycoprotein with multiple functions such as cellular adhesion, hyaluronate degradation, lymphocyte activation, angiogenesis, and cytokines release [33]; mouse anti-surfactant B (Fisher Scientific, Kalamazoo, MI) for detection of type II pneumocytes; CD24 (Santa Cruz Biotechnology, CA, USA), a cell adhesion molecule expressed by epithelial stem-like cells of the intralobar lung tissue [34]; and CD73 (BD Pharmingen, San Diego, CA), a second mesenchymal stem-like cell marker [35].

\section{Assessment of RILD}

We used Masson's trichrome staining for assessment of RILD pulmonary fibrosis. Slides taken from upper, middle and lower lobes of the right lungs of all rats were deparaffinised and rehydrated, then, washed in distilled water and stained with Weigert's iron hematoxylin working solution (Sigma Aldrich, Canada) for $10 \mathrm{~min}$. Slides were rinsed in warm running tap water for $10 \mathrm{~min}$ and washed in distilled water. Biebrich scarlet-acid fuchsin solution (Sigma Aldrich) was added for $15 \mathrm{~min}$, then, slides were washed in distilled water. Slides were then incubated in phosphomolybdic phosphotungstic acid solution (Sigma Aldrich) for $15 \mathrm{~min}$ and transferred immediately to aniline blue solution (Sigma Aldrich) for $10 \mathrm{~min}$. Slides were rinsed in distilled water then differentiated in $1 \%$ acetic acid solution (Sigma Aldrich) for $5 \mathrm{~min}$ 
Citation: Maria OM, Maria AM, Ybarra N, Jeyaseelan K, Lee S, et al. (2015) Investigation of Stem-like Cells Role in Regional Radiosensitivity of the Lung. J Stem Cell Res Ther 5: 298. doi:10.4172/2157-7633.1000298

Page 3 of 8

and washed in distilled water. Slides were finally dehydrated quickly through an alcohol series and cleared in xylene before being mounted with cover slips. Digital images of Masson's trichrome stained sections were captured at 40x magnifications with Leica camera mounted onto a Leica microscope by using Open lab image acquisition software. Image $\mathrm{J}$ analysis software (version 1.43d; NIH, USA) was used to quantify intensities of red and blue signals after Masson's trichrome staining. The algorithms in ImageJ program use a color deconvolution method to separate contributing colors. Using the red, green and blue (RGB) optical density vectors as determined by the software, each color was quantified individually for every image. The ratios of blue (collagen) and red (non-collagen) signal intensities were calculated to compare normalized collagen content [36]. Average ratios for each group were calculated as an indicator of fibrotic RILD. Haematoxylin and Eosin stained sections were prepared for morphological evaluation of the lung histology.

\section{Statistics}

Data are presented as means \pm standard deviation of results of all groups. The data were analyzed by one-way analysis of variance (ANOVA) where $\mathrm{p}$-values $<0.05$ represents significant differences among groups. Results obtained from immunohistochemistry and Masson's trichrome techniques are based on the examination of at least 5 slides per lobe taken from each animal. At least 1000 cells were examined per slide and the expression level of each marker/protein is indicated as a percentage; positive cells in relation to the total number of cells in the field for each marker. In all groups, the upper lobes were compared together and the lower lobes were compared together for each marker. In addition, in each group the upper and lower lobes were compared in each marker.

\section{Results}

\section{Stem-like cells distribution in normal lung}

The upper lobe of the control non-irradiated (rats sacrificed at 24 weeks of age) lung showed a higher percentage of surfactant B positive

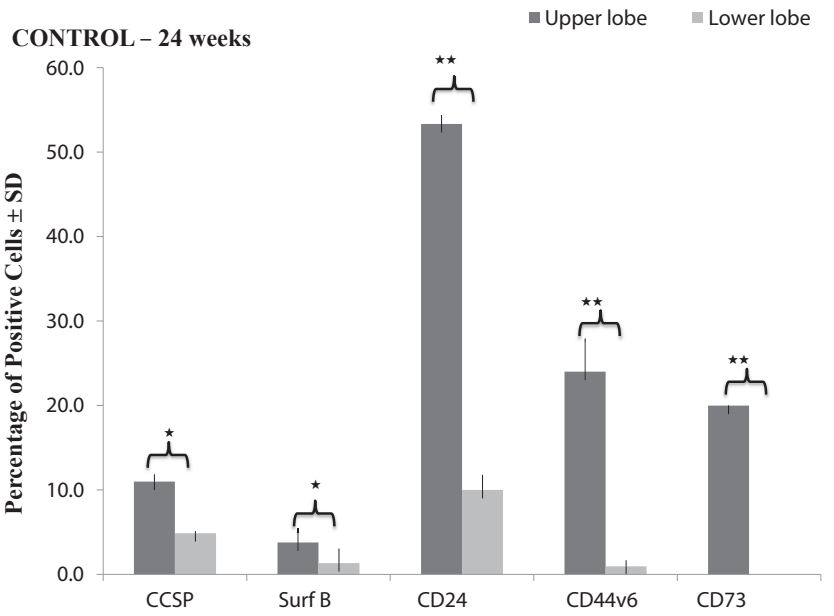

Figure 1: Mean percentage of positive cells \pm standard deviation for CCSP, Surfactant B, CD24, CD44v6, and CD73 in the upper and lower lung lobes of the control (non-irradiated, $0 \mathrm{~Gy}$ ) rats at 4 weeks of age. CCSP: Clara cell secretory protein for Clara cells, Surf B: surfactant B for type II pneumocytes. The percentage of positive cells in the upper lobe was compared to the percentage of the positive cells in the lower lobe for the same marker. Significance; ${ }^{*} p<0.05$ and ${ }^{* *} p<0.001$. cells (type II pneumocyes marker) and CCSP compared to the lower lobe ( $\mathrm{p}=0.024, \mathrm{p}=0.014$, respectively, Figure 1 ). Type II pneumocytes were mainly distributed in the lung parenchyma (Figure 2). Similarly, the percentages of CD24, CD44v6, CD73 positive cells were significantly higher $(\mathrm{p}<0.001$, Figure 1$)$ in the upper lobe compared to the lower lobe. CD24, CD44v6, CD73 positive cells were equally distributed in the tissue bronchioles and parenchyma, Figure 3 for CD44v6 and Figure 4 for CD73. However, Clara cells were not equally distributed in the bronchioles and parenchyma, Figure 5.

\section{Irradiated lung tissue}

Relative intensities of collagen deposition were compared in irradiated and non-irradiated upper and lower lung lobes of rats from all groups (Figure 6). A significant difference was observed in the collagen relative intensity of the upper and lower lobes of the control samples and the 12 Gy irradiated rats $(\mathrm{p}<0.001)$; the lower lobe showed more collagen deposition in both cases, a pattern that was washed out at higher doses. Moreover, the differences in collagen deposition in the lower lobes of control and the 12 Gy irradiated rats were significant $(p<0.01)$ when compared to the lower lobes of the 20 Gy irradiated animals. The differences in collagen deposition in the upper lobes of

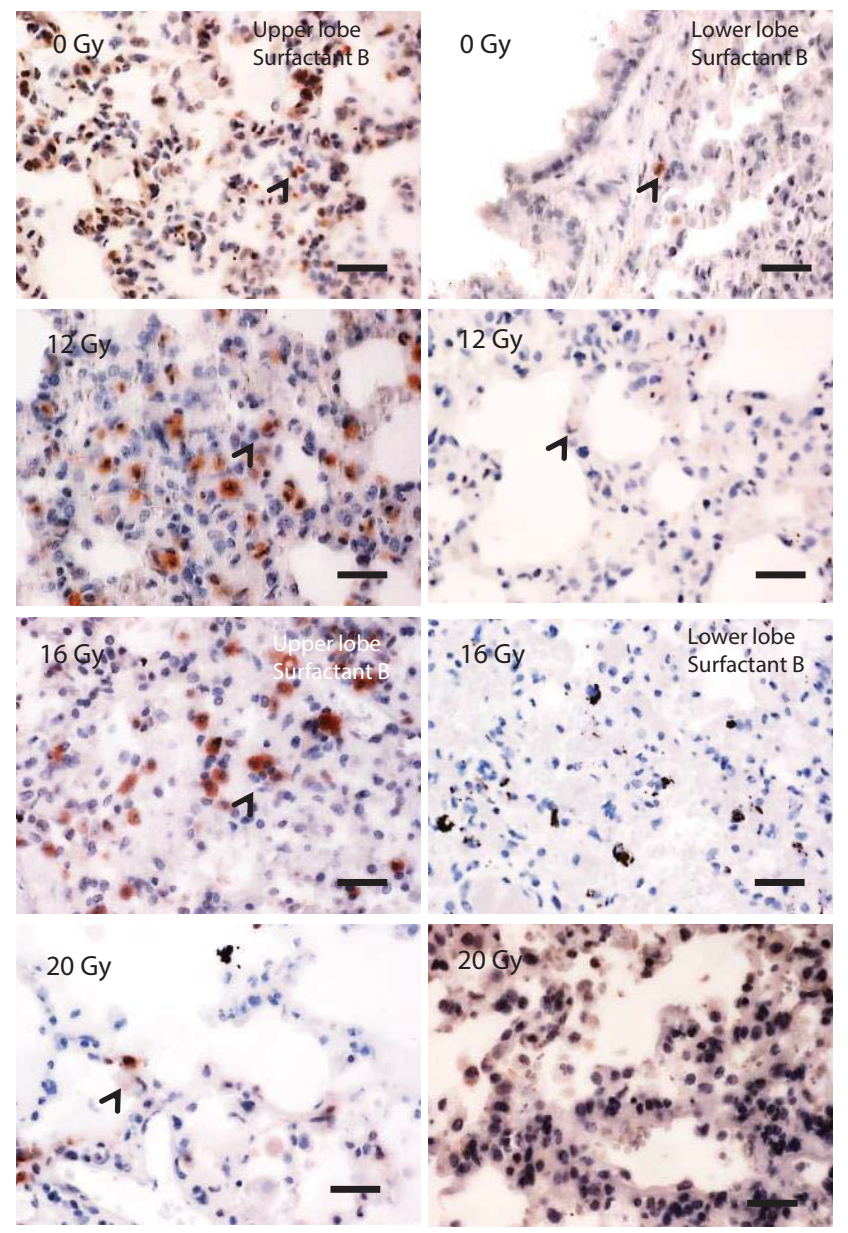

Figure 2: Immunohistochemically stained micrographs for surfactant b to localize type II pneumocytes in control (0 Gy), 12 Gy, 16 Gy, and $20 \mathrm{~Gy}$ irradiated rats. The left four micrographs are taken from the upper lung lobe while the right four are taken from the lower lung lobe. Arrows show positive reaction in different cells. Scale bar: $35 \mu \mathrm{m}$ at 400x. 

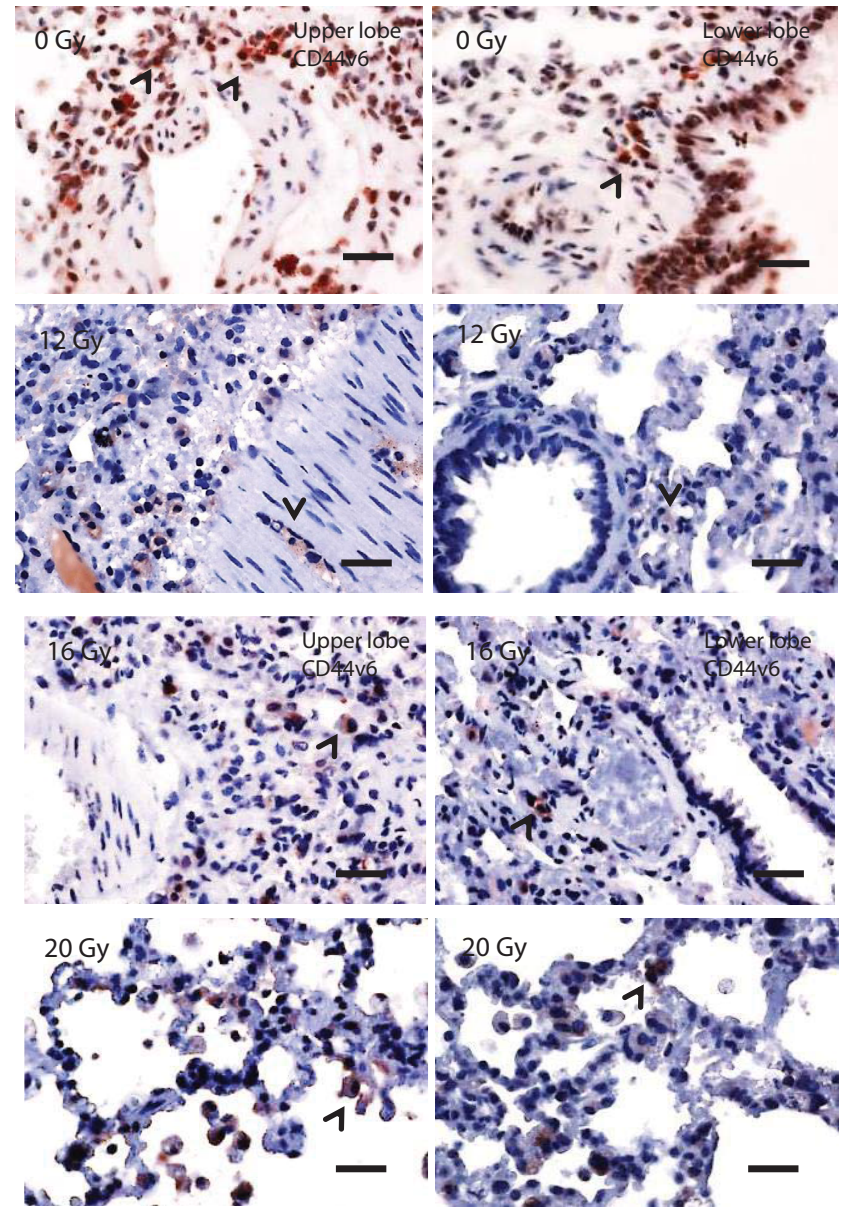

Figure 3: Immunohistochemically stained micrographs for CD44v6 positive cells in control (0 Gy), $12 \mathrm{~Gy}, 16 \mathrm{~Gy}$, and $20 \mathrm{~Gy}$ irradiated rats. The left four micrographs are taken from the upper lung lobe while the right four are taken from the lower lung lobe. Arrows show positive reaction in different cells. Scale bar: $35 \mu \mathrm{m}$ at $400 x$.

control rats were significant $(\mathrm{p}<0.001)$ when compared to the upper lobes of $16 \mathrm{~Gy}$ and $20 \mathrm{~Gy}$ irradiated animals. Figure 7 shows collagen deposition represented by trichrome stain in all groups.

\section{Effect of radiation on stem-like cells distribution}

Generally speaking, the distribution of tested stem-like cells in the lung tissue was approximately similar in all groups except the 12 Gy irradiated group; mostly in the bronchioles, fewer in the alveolar ducts and fewest in the alveoli. In the 12 Gy irradiated group, the stemlike cells distribution tended to increase in the alveoli and alveolar ducts compared to the bronchioles. Stem-like cells were seen around the blood vessels, which seemed to be their main source. The middle lobe percentages of stem-like cells were comparable to those in the lower lobe of the lung. Figures 2 - 5 show the distribution of type II pneumocytes, CD44v 6, CD73 and Clara cells in normal and irradiated groups in the upper versus the lower lobes.

In Figure 8, we summarize the results of the control versus irradiated rats in multiple plots for comparison purposes. The percentage of CCSP, Surfactant B, and CD44 positive cells in the upper lobes were significantly higher $(\mathrm{p}<0.01)$ in comparison to the lower lobe in $12 \mathrm{~Gy}$ irradiated rats. CD44v6 positive cells were seen migrating through the walls of the arteries/arterioles (Figure 3), where the lumens of small capillaries were positive to the CD44v6 protein; these cells were distributed equally in the parenchyma and the bronchioles. In the $16 \mathrm{~Gy}$ irradiated rats, only the percentage of CD44v6 positive cells in the lower lobes was significantly higher $(\mathrm{p}<0.01)$ in comparison to the upper lobe. In the $20 \mathrm{~Gy}$ irradiated rats, the percentages of CCSP, surfactant $\mathrm{B}, \mathrm{CD} 24$ and CD44v6 positive cells in the upper lobes were significantly higher $(p<0.001$ and $p<0.01)$ in comparison to the lower lobes, however, the difference of CD73 percentage was not significant $(\mathrm{p}=0.43)$, when the lower lobe was compared to the upper.

\section{Discussion}

In this study, we investigated the role of normal stem-like cells distribution in regional lung sensitivity to irradiation. An experimental rat model was used to test the hypothesis that variability in these cells regional distribution may be associated with variation in response to irradiation. It should be clarified that sensitivity to irradiation addressed in this study refers to the intrinsic cellular radiosensitivity and the effect of radiation on cells or functional subunits that leads to an overall organ function impairment following irradiation.

Our results suggest that the lower lobe reacts to radiation in a different manner compared to the upper lobe, in terms of radiosensitivity
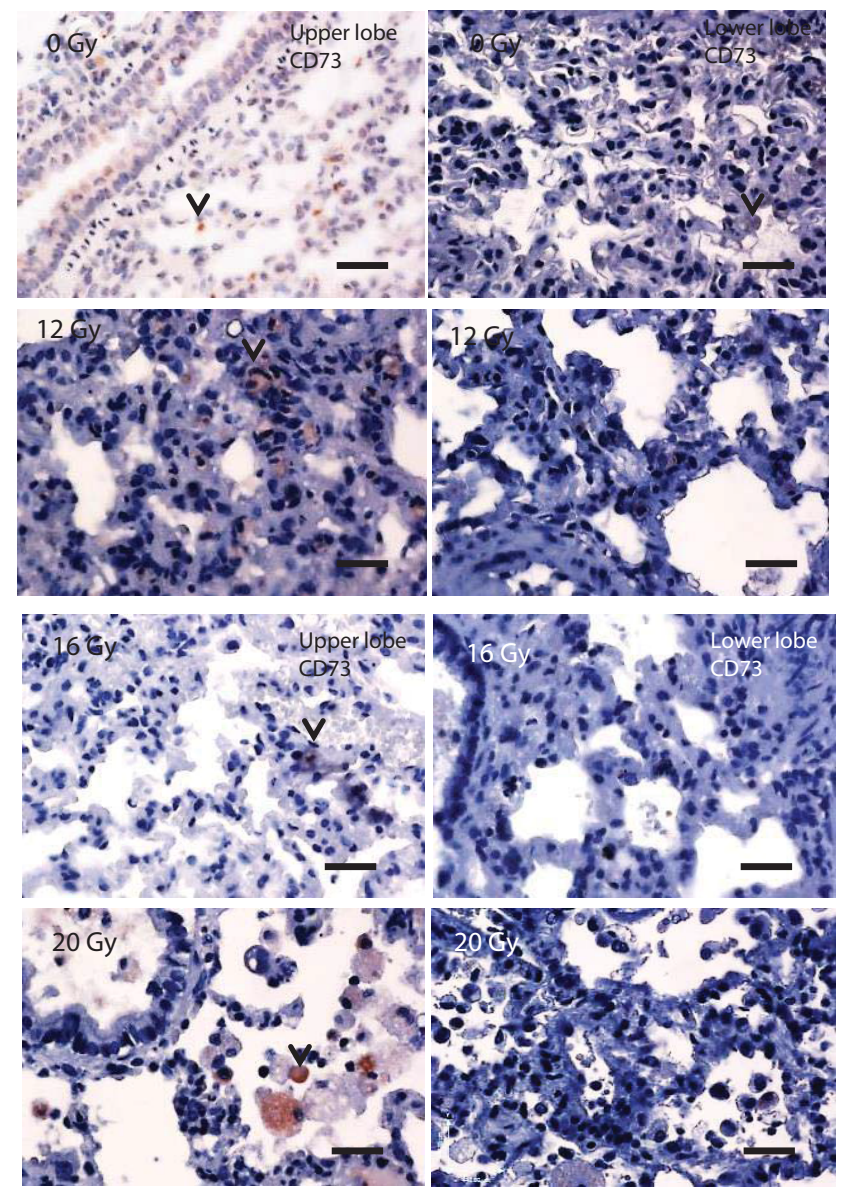

Figure 4: Immunohistochemically stained micrographs for CD73 positive cells in control $(0 \mathrm{~Gy}), 12 \mathrm{~Gy}, 16 \mathrm{~Gy}$, and $20 \mathrm{~Gy}$ irradiated rats. The left four micrographs are taken from the upper lung lobe while the right four are taken from the lower lung lobe. Arrows show positive reaction in different cells. Scale bar: $35 \mu \mathrm{m}$ at $400 \mathrm{x}$. 

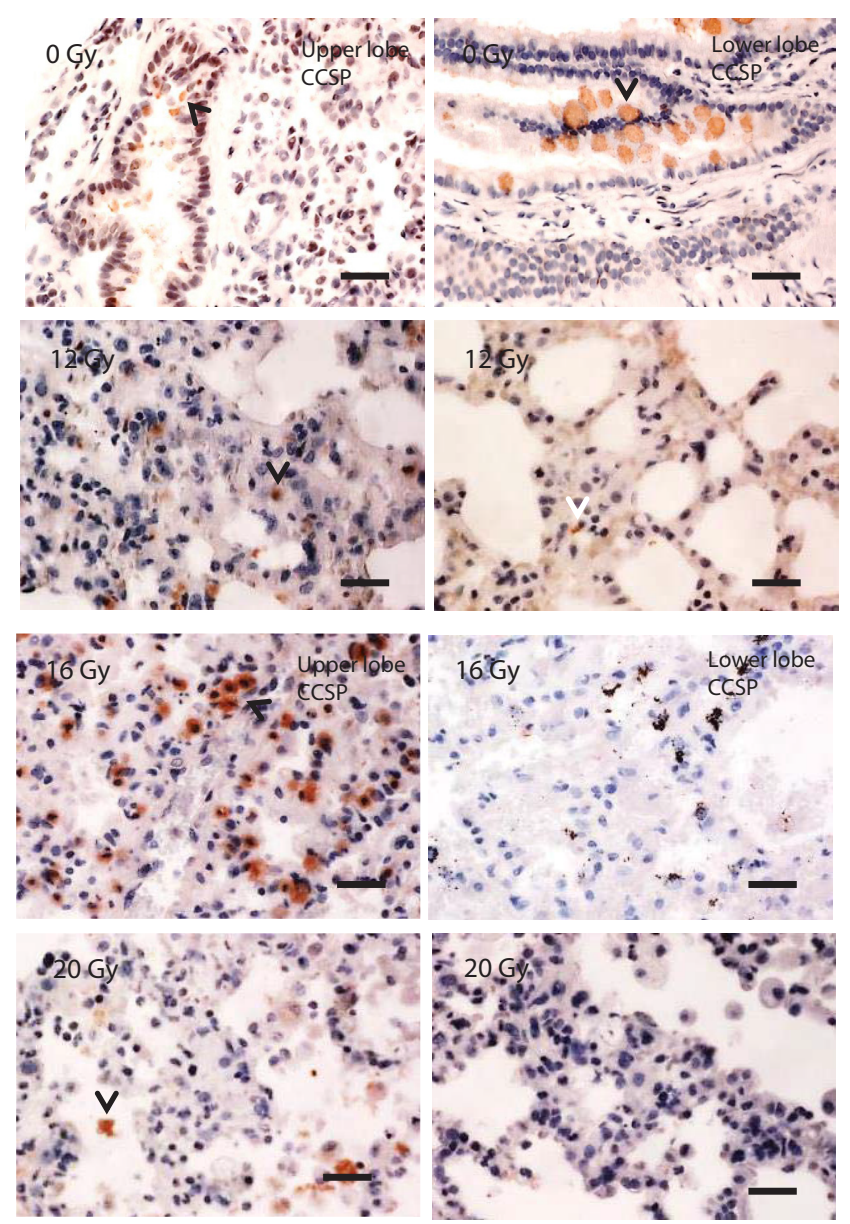

Figure 5: Immunohistochemically stained micrographs for Clara cell secretory protein positive cells to localize Clara cells in control (0 Gy), $12 \mathrm{~Gy}, 16 \mathrm{~Gy}$, and $20 \mathrm{~Gy}$ irradiated rats. The left four micrographs are taken from the upper lung lobe while the right four are taken from the lower lung lobe. Arrows show positive reaction in different cells. Scale bar: $35 \mu \mathrm{m}$ at $400 \mathrm{x}$.

or ability to recover from injury (Figure 6). A phenomenon that has been previously highlighted in several pre-clinical and clinical studies as discussed earlier. This work reports, for the first time to our knowledge, the potential role of stem-like cells in regional lung radiosenstivity. The selection of antibodies for these cells was based on reported literature (referred to in the materials and methods section) and commercially available antibodies against rats. We observed that these stem-like cells were mostly distributed in the bronchioles, fewer in the alveolar ducts and fewest in the alveoli in all groups except 12 Gy irradiated group where they tended to increase in the alveoli and alveolar ducts compared to the bronchioles. In irradiated groups, stem-like cells were seen around and/or moving through the blood vessels that seem to be their main origin [37] and may explain reported relationships with vascular damage [21] or heart radiation [19]. The upper lobe contained higher percentages of stem-like cells compared to the lower/middle lobes in normal non-irradiated rats except for Clara cells where the difference was not significant. In 12 Gy group, the upper lobe seemed to contain higher percentages of stem-like cells compared to the lower lobe except for CD24 and CD73. On the contrary in the 16 Gy group, the lower lobe showed higher percentage of CD44v6 compared to the upper lobe but the difference in the other stem-like cells content was not significant. In the 20 Gy group, the upper lobe showed higher content of stem-like cells in comparison to the lower lobe except for CD73. In the non-irradiated lung, 12 Gy and 16 Gy groups, sacrificed at 16 weeks post irradiation, the bronchioles showed higher distribution of most of the stem-like cells compared to the parenchyma, while the opposite was found in the 20 Gy group where rats were sacrificed at 4 weeks post irradiation. The content and distribution of stem-like cells might change

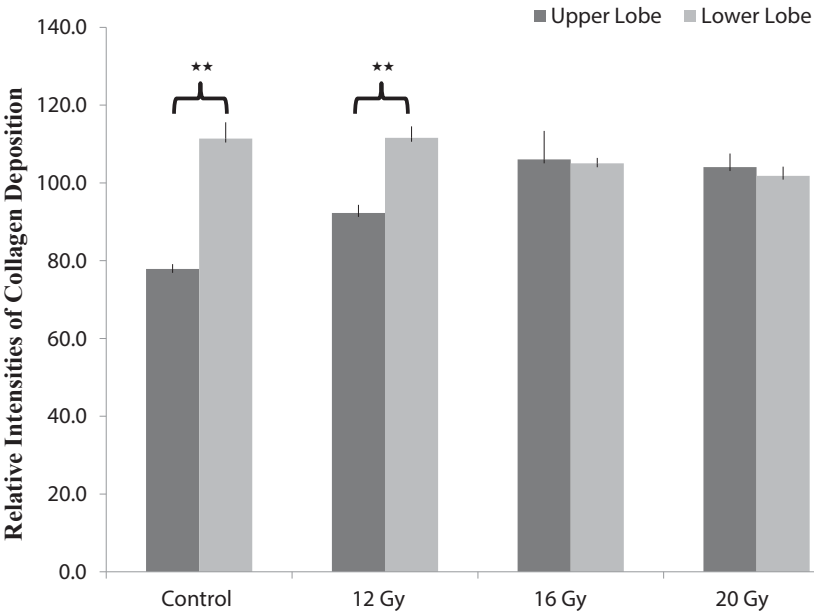

Figure 6: Scores of relative Masson's Trichrome staining intensity (Mean \pm standard deviation) for upper and lower lung lobes in each group, as an indication of collagen deposits and development of fibrosis. A significant difference was observed in the collagen relative intensity of the upper and lower lobes of the control samples and the $12 \mathrm{~Gy}$ irradiated rats $\left.{ }^{* *} \mathrm{p}<0.001\right)$; the lower lobe showed more collagen deposition. The differences in collagen deposition in the lower lobes of control and 12 Gy irradiated rats were significant $(p<0.01)$ when compared to the lower lobes of $20 \mathrm{~Gy}$ irradiated rats. The differences in collagen relative intensities in the upperlobes of control rats were significant $(p<0.001)$ when compared to the upper lobes of $16 \mathrm{~Gy}$ and $20 \mathrm{~Gy}$ irradiated rats. Control group, $12 \mathrm{~Gy}, 16 \mathrm{~Gy}$ were analysed at 24 weeks of age ( 16 weeks post irradiation) and 20 Gy at 12 weeks of age (4 weeks post irradiation).

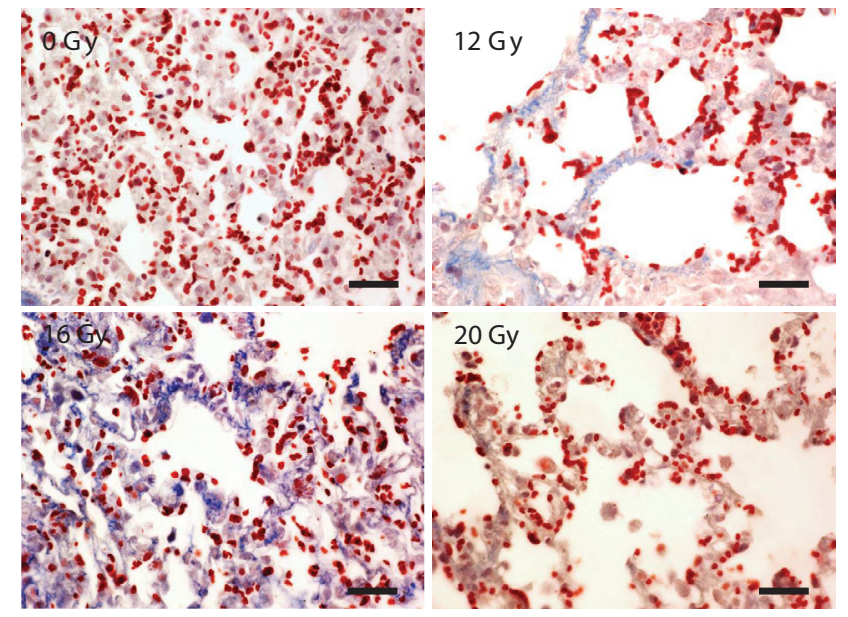

Figure 7: Masson's Trichrome stained micrographs to show collagen deposits and fibrosis development in each group. Control group (analyzed 16 weeks post irradiation) shows the least collagen content; 12 Gy group (analyzed 16 weeks post irradiation) shows higher collagen content compared to the control group; 16 Gy group (analyzed 16 weeks post irradiation) shows the highest collagen content; 20 Gy group (analyzed 4 weeks post irradiation) shows less collagen content compared to $12 \mathrm{~Gy}$ and $16 \mathrm{~Gy}$ groups. 
Citation: Maria OM, Maria AM, Ybarra N, Jeyaseelan K, Lee S, et al. (2015) Investigation of Stem-like Cells Role in Regional Radiosensitivity of the Lung. J Stem Cell Res Ther 5: 298. doi:10.4172/2157-7633.1000298
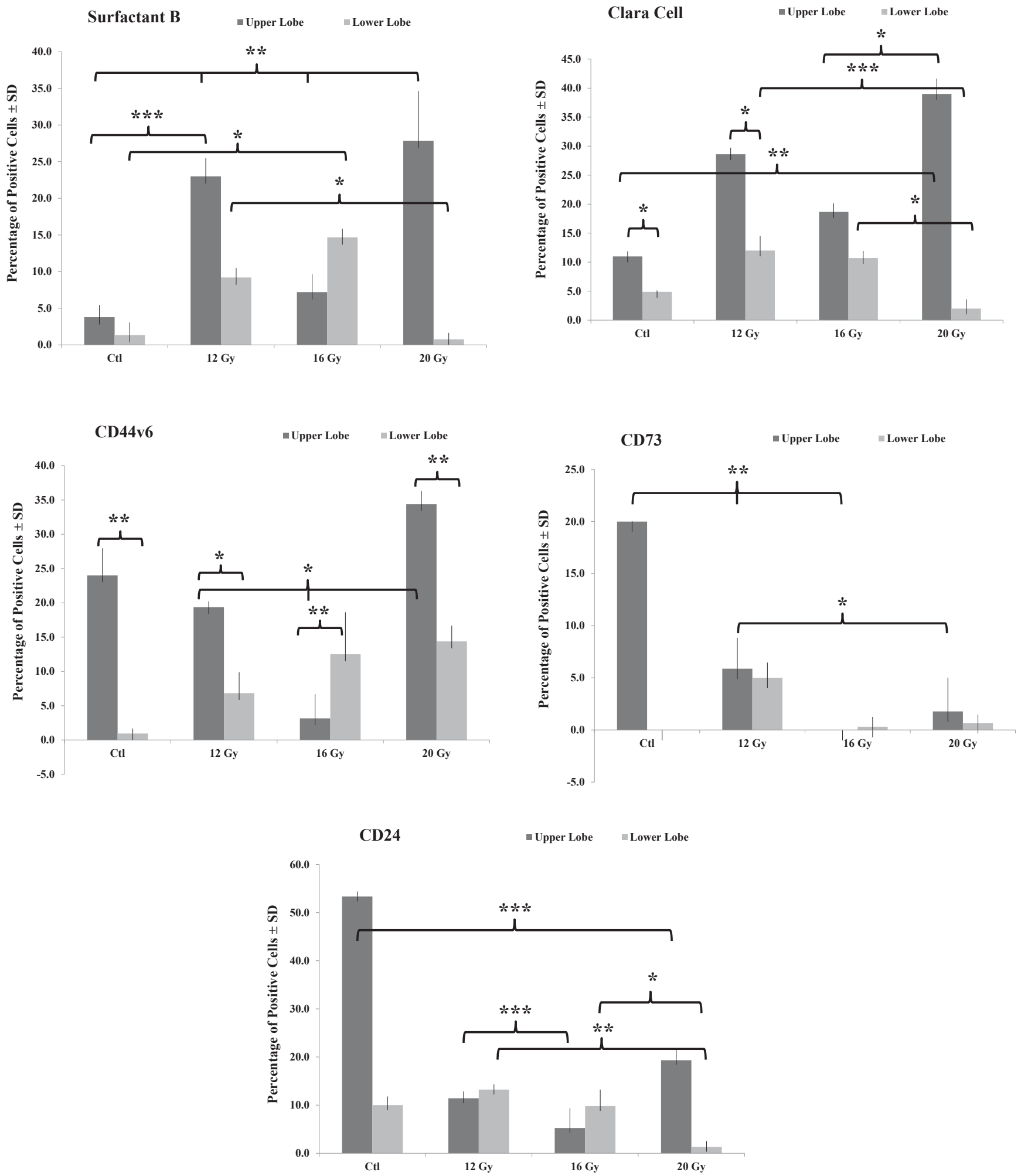

Figure 8: A plot of all stem-like cells biomarkers tested in this study, represented as mean percentage of positive cells for CCSP, Surfactant B, CD24, CD44v6, and CD73 in the upper and lower lung lobes of the control ( $0 \mathrm{~Gy}$ ), $12 \mathrm{~Gy}$ and 16 Gy irradiated rats at 24 weeks (16 weeks post irradiation) and 20 Gy irradiated rats at 12 weeks ( 4 weeks post irradiation). CCSP: Clara cell secretory protein for Clara cells, Surf B: surfactant B for type II pneumocytes. The percentage of positive cells in the upper lobe was compared to the percentage of the positive cells in the lower lobe for the same marker. In addition, the percentage of positive cells in the upper lobes were compared and the percentage of the positive cells in the lower lobes were compared, among all groups per marker. Significance; ${ }^{*}<<0.05$, ${ }^{* *} p<0.01$ and *** $\mathrm{p}<0.001$. 
with time post irradiation in concordance with the ablative radiation dose. There are two distinct circulatory systems that provide blood to the lungs; bronchial and pulmonary. The bronchial circulation provides oxygenated blood to the bronchi, large blood vessels and visceral pleura. The pulmonary circulation transports poorly oxygenated blood to the thin-walled alveoli, where carbon dioxide is removed and oxygen is added. Pulmonary arteries form a dense network of pulmonary capillaries at the level of the alveolar ducts. These capillaries empty into pulmonary veins, which carry oxygenated blood back to the heart [38]. The difference in the blood supply to bronchioles and alveoli seems to affect the content and distribution of stem-like cells among lobes and may explain the variation in their distribution following administration of different radiation doses; as part of their repair mechanism following injury. The severity of lung tissue injury and its repair capacity are, of course, affected by the radiation dose.

The significant increase in collagen deposition (fibrosis) in the lower lobe of 12 Gy irradiated rats (sacrificed at 16 weeks post irradiation) compared to the upper lobe was associated with significant decrease in stem-like cells in the lower lobe compared to the upper lobe. Increased fibrosis might be related to higher degree of tissue damage and inflammation that is associated with higher chances of stem-like cell loss/death or impaired repopulation and/or migration to the site of injury. In the $20 \mathrm{~Gy}$ irradiated rats, the percentages of stem-like cells in the upper lobes were significantly higher in comparison to the lower lobes, however, the differences in collagen deposition between the two lobes was not significant. These $20 \mathrm{~Gy}$ irradiated rats did not possibly develop sufficient fibrosis spread yet; as they were sacrificed at 4 weeks post irradiation due to increased morbidities. The differences in collagen deposition in the upper lobes of control rats were significant when compared to the upper lobes of 16 Gy but not 12 Gy irradiated rats. The higher the dose of radiation the higher the chance that all lung lobes would develop fibrosis. Some studies have proposed that adult stem cells reside in a localized specific microenvironment [28] that is commonly referred to as a stem cell niche [27]. In the current study, we were able to localize many stem-like cells, in situ, that were not necessarily residing in a niche but rather distributed unsystematically throughout the parenchyma/bronchioles.

Blood perfusion and lung ventilation show regional differences that are directed preferentially to the base of the lung. The hydrostatic pressure difference between the top and the base of the lung has a profound effect on the regional distribution of blood flow [39], which may explain the variability in the stem-like cells distribution themselves. The greater ventilation and perfusion at the base of the lung indicate a greater gas exchange rate at the base of the lung compared to the top [39]. This might suggest that the lower lobes would preferably harbour more differentiated type I pneumocytes to help in the load of gas exchange process. Our current observations are consistent with that reported in functional lung imaging studies by using Singlephoton emission computed (SPECT) to evaluate RILD [40,41]. Further investigation by using enhanced ventilation/perfusion SPECT (V/Q SPECT) imaging [42] might help address this issue.

\section{Conclusions}

In this study, we have shown that the upper lung lobe harbours more stem-like cells compared to the lower lobe, which may explain the variation in regional lung radiosensitivity, with the lower lobe being more prone to radiation injury compared to the upper lobe, as predicted from several experimental and clinical data. A possible interpretation of this variability could be related to stem-like cells distribution among lobes, which in turn might be explained by perfusion and ventilation processes in the lung. Stem-like cells population localized in this study were distributed unsystematically throughout the lung tissue in our experimental model, with no specific identifiable stem cell niche. However, further investigations are recommended to confirm or refute these findings in humans. A time course showing the evolution of RILD and changes in stem-like cell populations may be helpful to further establish the correlation between radiosenstivity and stemlike cell distribution difference. Clinically, our results may support the development of new targeted protectors of lung stem-like cells to reduce incidences of RILD in radiotherapy.

\section{Acknowledgments}

The authors are grateful to Dr. Simon Tran for microscopy support and Mr. Hyeunjoon Kim, summer intern in our laboratory. Part of this work was presented at ASTRO, 2012. This work was partially supported by Richard and Edith Strauss Postdoctoral Fellowship and CIHR grant MOP-114910. Authors would like to acknowledge the partial support by the CREATE Medical Physics Research Training Network grant of the Natural Sciences and Engineering Research Council; Grant number: 432290.

\section{References}

1. Marks LB, Yu X, Vujaskovic Z, Small W Jr, Folz R, et al. (2003) Radiationinduced lung injury. Semin Radiat Oncol 13: 333-345. [Pubmed]

2. Kong FM, Ten Haken R, Eisbruch A, Lawrence TS (2005) Non-small cell lung cancer therapy-related pulmonary toxicity: an update on radiation pneumonitis and fibrosis. Semin Oncol 32: S42-54. [Pubmed]

3. Ghafoori P, Marks LB, Vujaskovic Z, Kelsey CR (2008) Radiation-induced lung injury. Assessment, management, and prevention. Oncology (Williston Park) 22: 37-47. [Pubmed]

4. Bradley JD, Hope A, El Naqa I, Apte A, Lindsay PE, et al. (2007) A nomogram to predict radiation pneumonitis, derived from a combined analysis of RTOG 9311 and institutional data. Int J Radiat Oncol Biol Phys 69: 985-992. [Pubmed]

5. Linda A, Trovo M, Bradley JD (2011) Radiation injury of the lung after stereotactic body radiation therapy (SBRT) for lung cancer: a timeline and pattern of CT changes. Eur J Radiol 79: 147-154. [Pubmed]

6. Trovo M, Linda A, El Naqa I, Javidan-Nejad C, Bradley J (2010) Early and late lung radiographic injury following stereotactic body radiation therapy (SBRT) Lung Cancer 69: 77-85. [Pubmed]

7. Ward WF, Lin PJ, Wong PS, Behnia R, Jalali N (1993) Radiation pneumonitis in rats and its modification by the angiotensin-converting enzyme inhibitor captopril evaluated by high-resolution computed tomography. Radiat Res 135:81-87.

8. Hallahan DE, Virudachalam S (1997) lonizing radiation mediates expression of cell adhesion molecules in distinct histological patterns within the lung. Cancer Res 57: 2096-2099. [Pubmed]

9. Ward PA, Hunninghake GW (1998) Lung inflammation and fibrosis. Am J Respir Crit Care Med 157: S123-129. [Pubmed]

10. Travis EL, Liao ZX, Tucker SL (1997) Spatial heterogeneity of the volume effect for radiation pneumonitis in mouse lung. Int J Radiat Oncol Biol Phys 38: 10451054. [Pubmed]

11. Tucker SL, Liao ZX, Travis EL (1997) Estimation of the spatial distribution of target cells for radiation pneumonitis in mouse lung. Int $\mathrm{J}$ Radiat Oncol Biol Phys 38: 1055-1066. [Pubmed]

12. Moiseenko VV, Battista JJ, Hill RP, Travis EL, Van Dyk J (2000) In-field and outof-field effects in partial volume lung irradiation in rodents: possible correlation between early dna damage and functional endpoints. Int J Radiat Oncol Biol Phys 48: 1539-1548. [Pubmed]

13. Wiegman EM, Meertens H, Konings AW, Kampinga HH, Coppes RP (2003) Loco-regional differences in pulmonary function and density after partial rat lung irradiation. Radiother Oncol 69: 11-19. [Pubmed]

14. Trott KR, Herrmann T, Kasper M (2004) Target cells in radiation pneumopathy Int J Radiat Oncol Biol Phys 58: 463-469. [Pubmed]

15. Yorke ED, Jackson A, Rosenzweig KE, Braban L, Leibel SA, et al. (2005) Correlation of dosimetric factors and radiation pneumonitis for non-small-cell lung cancer patients in a recently completed dose escalation study. Int J Radiat Oncol Biol Phys 63: 672-682. [Pubmed] 
Citation: Maria OM, Maria AM, Ybarra N, Jeyaseelan K, Lee S, et al. (2015) Investigation of Stem-like Cells Role in Regional Radiosensitivity of the Lung. J Stem Cell Res Ther 5: 298. doi:10.4172/2157-7633.1000298

Page 8 of 8

16. Hope AJ, Lindsay PE, El Naqa I, Alaly JR, Vicic M, et al. (2006) Modeling radiation pneumonitis risk with clinical, dosimetric, and spatial parameters. Int $J$ Radiat Oncol Biol Phys 65: 112-124. [Pubmed]

17. Khan MA, Van Dyk J, Yeung IW, Hill RP (2003) Partial volume rat lung irradiation; assessment of early DNA damage in different lung regions and effect of radical scavengers. Radiother Oncol 66: 95-102. [Pubmed]

18. Hill RP (2005) Radiation effects on the respiratory system. BJR Suppl 27:75-81.

19. Novakova-Jiresova A, van Luijk $P$, van Goor $H$, Kampinga $H H$, Coppes RP (2005) Pulmonary Radiation Injury: Identification of Risk Factors Associated with Regional Hypersensitivity. Cancer Res 65:3568-3576.

20. Brown WR, Thore CR, Moody DM, Robbins ME, Wheeler KT (2005) Vascular damage after fractionated whole-brain irradiation in rats. Radiat Res 164: 662 668. [Pubmed]

21. Peterson LM, Evans ML, Graham MM, Eary JF, Dahlen DD (1992) Vascular response to radiation injury in the rat lung. Radiat Res 129: 139-148. [Pubmed]

22. Huang EX, Hope AJ, Lindsay PE, Trovo M, El Naqa I, et al. (2011) Heart irradiation as a risk factor for radiation pneumonitis. Acta Oncol 50: 51-60. [Pubmed]

23. Herzog EL, Chai L, Krause DS (2003) Plasticity of marrow-derived stem cells. Blood 102: 3483-3493. [Pubmed]

24. Maria OM, Tran SD (2011) Human mesenchymal stem cells cultured with salivary gland biopsies adopt an epithelial phenotype. Stem Cells Dev 20: 959967. [Pubmed]

25. Sumita Y, Liu Y, Khalili S, Maria OM, Xia D, et al. (2011) Bone marrow-derived cells rescue salivary gland function in mice with head and neck irradiation. Int $\mathrm{J}$ Biochem Cell Biol 43: 80-87. [Pubmed]

26. Otto WR (2002) Lung epithelial stem cells. J Pathol 197: 527-535. [Pubmed]

27. Schofield R (1983) The stem cell system. Biomed Pharmacother 37: 375-380. [Pubmed]

28. Kajstura J, Rota M, Hall SR, Hosoda T, D'Amario D, et al. (2011) Evidence for human lung stem cells. N Engl J Med 364: 1795-1806. [Pubmed]

29. Kotton DN, Ma BY, Cardoso WV, Sanderson EA, Summer RS, et al. (2001) Bone marrow-derived cells as progenitors of lung alveolar epithelium. Development 128: 5181-5188. [Pubmed]

30. Krause DS, Theise ND, Collector MI, Henegariu O, Hwang S, et al. (2001)
Multi-organ, multi-lineage engraftment by a single bone marrow-derived stem cell. Cell 105: 369-377. [Pubmed]

31. Theise ND, Henegariu O, Grove J, Jagirdar J, Kao PN, et al (2002) Radiation pneumonitis in mice: a severe injury model for pneumocyte engraftment from bone marrow. Exp Hematol 30:1333-1338.

32. Kotton DN, Fine A (2003) Derivation of lung epithelium from bone marrow cells Cytotherapy 5: 169-173. [Pubmed]

33. Sneath RJ, Mangham DC (1998) The normal structure and function of CD44 and its role in neoplasia. Mol Pathol 51: 191-200. [Pubmed]

34. McQualter JL, Yuen K, Williams B, Bertoncello I (2010) Evidence of an epithelia stem/progenitor cell hierarchy in the adult mouse lung. Proc Natl Acad Sci U S A 107: 1414-1419. [Pubmed]

35. Barry F, Boynton R, Murphy M, Haynesworth S, Zaia J (2001) The SH-3 and $\mathrm{SH}-4$ antibodies recognize distinct epitopes on CD73 from human mesenchymal stem cells. Biochem Biophys Res Commun 289: 519-524. [Pubmed]

36. Krajewska M, Smith LH, Rong J, Huang X, Hyer ML, et al (2009) Image analysis algorithms for immunohistochemical assessment of cell death events and fibrosis in tissue sections. J Histochem Cytochem 57:649-663.

37. Prockop DJ, Gregory CA, Spees JL (2003) One strategy for cell and gene therapy: harnessing the power of adult stem cells to repair tissues. Proc Nat Acad Sci U S A 100 Suppl 1: 11917-11923. [Pubmed]

38. Powell $F$ (2003) Structure and function of the respiratory system: Essentia Medical Physiology. (2nd edn), Johnson L., Amsterdam, Boston, Elsevier Academic Press.

39. Powell F (2003) Pulmonary gas exchange: Essential Medical Physiology (2ndedn), Johnson L., Amsterdam, Boston, Elsevier Academic Press.

40. Marks LB, Spencer DP, Sherouse GW, Bentel G, Clough R, et al. (1995) The role of three dimensional functional lung imaging in radiation treatment planning: the functional dose-volume histogram. Int J Radiat Oncol Biol Phys 33: 65-75. [Pubmed]

41. Marks LB, Munley MT, Spencer DP, Sherouse GW, Bentel GC, et al. (1997) Quantification of radiation-induced regional lung injury with perfusion imaging Int J Radiat Oncol Biol Phys 38: 399-409. [Pubmed]

42. Bajc M, Neilly B, Miniati M, Mortensen J, Jonson B (2010) Methodology for ventilation/perfusion SPECT. Semin Nucl Med 40: 415-425. [Pubmed] 